Sanna Hirvonen *

University College London

\title{
How MODERATE RELATIVISTS SHOULD EXPLAIN THE APPEARANCE OF DISAGREEMENTS ABOUT TASTE
}

\begin{abstract}
Moderate relativists such as Kölbel (2003, 2009) and Lasersohn (2005) have motivated the semantic framework by arguing that unlike contextualism, it can explain why there appear to be disagreements of taste. The solution relies on the relativist notion of a proposition whose truth depends on a judge parameter. This notion coupled with the view that contradicting propositions create an appearance of disagreement allegedly enables them to secure the right predictions. This paper questions the argumentative strategy by showing that there are no basis to infer pragmatic data (an appearance of disagreement) from formal semantics (locating an element of truth-conditions to the circumstance rather than propositional content). I then present a way to understand the relativist framework from the point of view of mental representation. The view put forward explains the missing relation between the semantic framework and pragmatics, and predicts why there is an appearance of disagreements about taste.
\end{abstract}

\section{Keywords}

moderate relativism, predicates of taste, disagreement.

\footnotetext{
* Department of Philosophy University College London Gower Street WC1E 6BT London, United Kingdom e-mail: sanna.hirvonen.09@ucl.ac.uk
} 
How Moderate Relativists Should Explain the Appearance of Disagreements about Taste

\section{Moderate relativism in a nutshell}

Moderate relativism (also known as non-indexical contextualism) and radical relativism are novel semantic frameworks which have surfaced during the last 10 years (see for example Kölbel 2002, MacFarlane 2009, Recanati 2007). Let me first summarise Kaplan's (1989) semantics which we will use in our characterisations of what makes semantics relativist. Kaplan distinguishes between a proposition (or content) which is determined by the characters of the expressions in the sentence and the context of utterance, and a circumstance of evaluation, a situation which determines which truth value the proposition that is expressed gets. Hence propositional truth depends on the proposition expressed and the circumstance of evaluation. Which circumstance of evaluation is the relevant one for a particular utterance is fixed by the context of utterance, but it need not be the circumstance of the context.

Now, what makes a semantic framework relativist in the sense we are interested in is the idea that propositions are true or false relative to something more than just a world of evaluation, i.e. the circumstance of evaluation contains other parameters than just a world parameter (Kölbel 2009). For example, one can think of tenses as provided by the circumstance of evaluation rather than an element of the propositional content (Kaplan 1989). Other parameters that have been defended include locations to account for how utterances which do not explicitly mention a location can be true (Recanati 2007), epistemic standards (Stephenson 2007) and standards of taste (Lasersohn 2005, Stephenson 2007, Kölbel 2003).

To summarise the basic idea, we may present semantic relativism as endorsing two core tenets:

Duality. To get a truth-value, we need a circumstance of evaluation as well as a content to evaluate.

Distribution. The determinants of truth-value distribute over the two basic components truth-evaluation involves: content and circumstance. That is, a determinant of truth-value, e.g. a time, is either given as an ingredient of content or as an aspect of the circumstance of evaluation. (Recanati 2007: 33-34)

The consequence of distribution is that the more parameters the relativist adds, the more incomplete the contents to be evaluated are. Hence, for the relativist, contents are merely propositional functions, i.e. express functions from, for example, time, world and agent triples to truth values. The tradition that dates back to Frege takes propositions as having a truth value absolutely, but it is noteworthy that the Kaplanian semantics takes propositions to get a truth value only relative to a world.

In this paper we will focus on relativism about taste predicates (e.g. delicious, fun and tasty) which is the most popular form of relativism in the recent literature. 
Lodz Papers in Pragmatics 7.2 (2011)/Special Issue on Context and Contextualism: 223-240 DOI: $10.2478 / \mathrm{v} 10016-011-0012-7$

The view holds that the truth of taste judgments depends on "standards of taste" but the content of taste predicates does not refer to standards of taste. Therefore, taste statements get a truth value only relative to a given judge. Moreover, relativists about taste hold that it is the standards of taste of the speaker which are typically relevant for the truth of an utterance (with the exception of Recanati (2007) who takes the relevant standards to be those of the community to which the speaker belongs).

The core semantic idea is that the circumstance of evaluation contains a judge parameter which needs a value for a statement about taste to get a truth value. For example, the proposition Tofutti is better than cream cheese does not have a truth value until we fix on a circumstance of evaluation, i.e. choose a standard of taste and a possible world. ${ }^{1}$ Hence the very same proposition can be true at a circumstance of evaluation with e.g. my standards of taste and the actual world, but false at your standards of taste and the actual world. Let us next look at the motivations that have been given in favour of such a view.

\section{Motivation for moderate relativism}

To understand the main motivation for moderate relativism about taste predicates we need to look at the dialectical strategy underlying the defences of relativist semantics for taste predicates used by e.g. Lasersohn (2005), Kölbel (2003) and Kölbel (2009). First, the relativist offers an argument against simple contextualism about predicates of taste which construes them as indexicals that refer to the speaker:

(1) Uses of sentences express propositions.

(2) There is an appearance of disagreement iff one expresses a proposition and another expresses a proposition which contradicts the previous one. ${ }^{2}$

(3) Whether judgments of taste are true or false depends typically on the taste of the speaker (and sometimes on the taste of some other relevant individual).

(4) There are appearances of disagreements about taste.

(5) If taste predicates refer to speakers in the manner of indexicals

\footnotetext{
${ }^{1}$ Tofutti is a tofu-based imitation cream cheese which is advertised with the slogan Better than cream cheese.

${ }^{2}$ I say one and another just to avoid a syntactically weird subjectless sentence, but naturally these can refer to the same person at different times. We will discuss in the next section why we formulate the premise in terms of appearance of disagreement rather than disagreement.
} 
How Moderate Relativists Should Explain the Appearance of Disagreements about Taste

(i.e., the speaker is part of the proposition expressed), then there are no appearances of disagreements of taste. ${ }^{3}$

(C) Taste predicates do not refer to speakers in the manner of indexicals. (By 1-5). The positive case is an inference to the best explanation which takes (1)-(4) as the key facts to be explained. The suggestion is that the "judge" whose taste is at issue is akin to parameters like world and time. Hence, propositions get evaluated relative to worlds and judges (and possibly other parameters), which allows for subjectivism about evaluative taste properties (3). But given premise (2), relativism gets to say that there are disagreements about taste (4).

\section{3. "Faultless disagreements"?}

The argument above has been criticised especially due to the dubious status of premise (2) that appearance of disagreement requires that agents accept contradictory propositions. Moreover, the main formulations of the above argument in the literature tend to be unclear regarding how premise (2) gets formulated: sometimes one encounters the claim made regarding disagreements, sometimes appearances of disagreements. Lasersohn (2005) switches between talk of contradicting propositions and disagreements. Kölbel himself states the following in his original paper on "faultless disagreements":

A faultless disagreement is a situation where there is a thinker $A$, a thinker $B$, and a proposition (content of judgement) $p$, such that:

(a) $A$ believes (judges) that $p$ and $B$ believes (judges) that not- $p$

(b) Neither $A$ nor $B$ has made a mistake (is at fault).

I believe that most people have a healthy pre-theoretical intuition that there can be and are faultless disagreements in this sense. (Kölbel 2003: 53-54)

However, Kölbel later emphasises that he had coined the term without intending to imply that "faultless disagreements" are either disagreements or faultless in any "pre-theoretical" sense (Kölbel 2009: 389). Lasersohn concludes his discussion on relativist disagreement as follows:

\footnotetext{
${ }^{3}$ This is because (2) will not hold. To illustrate, when Mary utters This sauerkraut is delicious, she expresses the proposition "Sauerkraut is delicious for Mary". If Peter answers "No, this sauerkraut is totally not delicious" he expresses the proposition "No, this sauerkraut is totally not delicious for Peter", and hence by (2) there is no appearance of disagreement.
} 
Lodz Papers in Pragmatics 7.2 (2011)/Special Issue on Context and Contextualism: 223-240 DOI: $10.2478 / \mathrm{v} 10016-011-0012-7$

The fact remains that in this analysis there is no matter of fact on which disagreements of taste turn. Such disagreements are in some sense "without substance". More, no doubt, should be said to clarify and justify the notion of "substanceless" disagreement, but this too will be left to further investigation. (Lasersohn 2005: 684)

Hence, it may very well be that both Kölbel and Lasersohn never intended to claim that there was anything like "genuine disagreement" going on in taste disagreements, but the impression to the contrary has sparked a lot of criticism as well as useful clarifications of the different notions of disagreement. ${ }^{4}$

I have reconstructed the argument following Kölbel (2009) who emphasises that the argument relies on the appearance of disagreement and is neutral as regards to whether there is disagreement. A final remark on the appearance of disagreement: I assume that an object may appear to be $F$ to one and not $F$ to another. When I say there is an appearance of disagreement, I mean that it appears to both (or all) of the speakers that there is disagreement between them. Let us next see in more detail how the relativist's inference to the best explanation proceeds.

\section{Moderate relativism and communication}

As we saw in Section (1), the essence of moderate relativism is the following: instead of taking truth to be a function from worlds to truth values they distribute the elements between the proposition and parameters at the circumstance of evaluation so that propositions get a truth value only once the values of those parameters are fixed. But the argument for relativism relies on its alleged ability to predict certain linguistic data, namely the appearance of disagreements. Hence we need to understand what is the link between the formal semantic framework and the appearance of disagreement. In this section we will reconstruct the relativists' pronouncements about their semantic framework and its pragmatics into a coherent story about communication using a suitably modified Stalnakerian framework about assertion.

As we have seen, both Kölbel and Lasersohn assume that the appearance of disagreement requires that one accepts a proposition and another accepts a proposition which contradicts the first one. And both assume that merely contradicting sentences do not suffice for an appearance of disagreement. For example, when I say I'm a doctor and you say I'm not a doctor there is no appearance of disagreement. A natural reason to think that mere sentences do not make for appearances of disagreement is that they play a secondary role in

\footnotetext{
${ }^{4}$ See e.g. MacFarlane (2007) and Sundell (2010) on what kind of disagreements there are and can be predicted by contextualist and relativist theories.
} 
communication: they are simply the means for expressing propositions which are what is communicated by assertions.

Following Stalnaker (1978) we may hold that the point of assertions is to modify the presuppositions of the participants to the conversation, that is, the propositions each participant takes for granted for the purposes of the conversation (also known as the context set). To accept a proposition is to modify one's presuppositions accordingly (by excluding propositions incompatible with the proposition accepted). However, the Stalnakerian model of communication is based on the idea of communication as putting forward propositions which are true or false relative to worlds but not to further parameters. Given that we are now dealing with relativised propositions, how should we modify the picture of communication?

Stalnaker thinks of propositions in terms of possible worlds or ways the world could be. Communication aims at finding out which of those ways is the way the actual world is. By gaining knowledge we exclude possibilities, so for example an omniscient being would be one who has excluded every possible world except the actual one. Relativists take the proposition expressed to be judge-neutral in the case of taste. So the speaker only puts forward a judge-neutral proposition which does not get a truth value before a value for the judge parameter is fixed.

To illustrate, let us think of a particular case. Imagine that John and Peter are making Halloween costumes, and John says Making Halloween costumes is fun. Now, the relativists take speakers to typically assert from their own point of view, i.e. John asserts that making Halloween costumes is fun because it is true given his standards of fun. So once the act of assertion has taken place, what is the information Peter receives? The proposition itself carries little information since it is neither true nor false unless a particular value for the judge parameter has been provided. So the hearer needs to evaluate the proposition relative to some standards of fun, but the question is which one? Here is what Kölbel and Lasersohn have to say about that:

There are many ways of evaluating utterances: when Anna saysthat whale meat is tasty, I can evaluate what she says against her own standard of taste, against my own standard, or against some other person's. Thus, her utterance can be correct on her standard, my standard, someone else's standard. (Kölbel 2009: 387)

The relativist [...] claims that in certain areas such as matters of taste, not everyone is required to believe in accordance with the same representation, not everyone is subject to the same standard. It may be correct for one person to believe that whale meat is tasty and correct for another to believe that it is not. There is more than just one true representation to which everyone is supposed to conform. (Kölbel 2009: 388) 
Lodz Papers in Pragmatics 7.2 (2011)/Special Issue on Context and Contextualism: 223-240 DOI: $10.2478 / \mathrm{v} 10016-011-0012-7$

In order to maintain an authentically subjective assignment of truth values to sentences containing predicates of personal taste, we must allow that the objective facts of the situation of utterance do not uniquely determine a judge. (Lasersohn 2005: 669)

All this having been said, I think we must recognise that when we do assess an utterance for truth or falsity, we all normally tend to use ourselves as the judge; or, as I shall put it, we adopt an autocentric perspective. [...] This is true regardless of whether we are the speaker, addressee, or a third party: we typically evaluate our own assertions, and those of others, from our own perspective. (Lasersohn 2005: 670)

What emerges is the following picture of communication with incomplete propositions: a speaker asserts a proposition which she takes to be true given her standard of taste. The hearer then has a choice regarding which standards of taste she uses to evaluate the proposition, although typically she will evaluate it from the point of view of her standards of taste.

So returning to the picture of communication where propositions modify presuppositions, what happens if Peter evaluates the proposition expressed relative to his own standards of fun and the proposition gets the truth value true? Presumably he excludes from his context set the world-judge pairs in which making Halloween costumes is not fun. Hence, if he knew everything about the world and his own taste, he would have excluded every world-judge pair except the actual world and his standard of taste.

But what if the proposition is false? Presumably the suggestion to modify the presuppositions is rejected, which is expressed by uttering, for example, That's false. Let us next clarify an important but neglected aspect of the relativist picture.

\section{Propositional attitude reports}

Suppose that the proposition "Making Halloween costumes is fun" happens to be true for Peter as a judge so he agrees, and excludes from his presuppositions any world-judge pair incompatible with "Making Halloween costumes is fun". Later, Peter talks on the phone with Mary who asks Did John also think that making costumes was fun? Now, what will Peter say?

Given the relativist's account of what creates the appearance of disagreement (i.e. premise (2), p. 4), what is linguistically expressed must be nothing but the proposition: otherwise there is not even "faultless" or "substanceless" disagreement. But an assertion typically conveys information also by other means than via the propositions expressed. As Stalnaker (1978) emphasises, an assertion (successful or not) modifies the presuppositions also because the hearer adds to 
them the fact that an assertion of such-and-such a proposition was made by a certain person.

Assertion thus works in two ways: the content of assertion is a proposal to modify the presuppositions, and the act of assertion is a salient fact which everyone takes for granted once it has taken place. Other salient facts of the situation work the same way; e.g. if there is an earthquake, the participants add that information to their presuppositions. In our case we can then consider the two ways Peter gains information: via the content of John's utterance of Making Halloween costumes is fun, and via the fact that John made an utterance with that content.

Let us first think of how Peter could answer the question based on the content of the assertion. Now, Mary's question was Did John also think that making costumes was fun? This could mean at least two things in the relativist framework:

(i) Did John think the proposition "Making Halloween costumes is fun" is true? and

(ii) Did John think the proposition "Making Halloween costumes is fun" is true given his standards of fun?

Let us suppose that Mary asked the question (ii) which corresponds to the intuitive sense of the question. Now, we want an account that explains how Peter can answer yes. Given what John expressed, namely the judge-neutral proposition, Peter cannot know whether John only thought that the proposition is true, or it is true given his standards of fun. So based on the information conveyed by the proposition, Peter could only answer something like He said it's fun, but I don't know whether he was talking about himself. So the proposition is not enough to communicate the relevant information. How about the fact that the assertion took place; will it provide the right answer?

There are various norms that govern conversations and, as Grice (1989) argued, blatant violations of the norms enable conveying information by e.g. conversational implicatures. Hence the relativist could argue that given the norms that govern the making of assertions the hearer is able to infer that the speaker holds certain attitudes towards the proposition she expressed. Below is a quotation from Kölbel (2009) which gives some idea of the norms he takes to govern assertions:

It is worth mentioning, that the relativist position involves a particular take on talk of a "fault" in (d) [i.e. when two agents engage in "faultless disagreements"]. The idea is that individuals are, for example, subject to the norm that they should believe and assert only propositions that are true at the actual world and on their own standard of taste, and that being at "fault" in the sense of (d) involves violating a norm one is subject to. (Kölbel 2009: 390) 
Lodz Papers in Pragmatics 7.2 (2011)/Special Issue on Context and Contextualism: 223-240 DOI: $10.2478 / \mathrm{v} 10016-011-0012-7$

The way to explain how Peter got the information about John's attitude towards the proposition he expressed could then be as follows: The norm of belief and assertion states that one must believe and assert only propositions that are true in the actual world and on the standard of taste (in this case standard of fun) of the speaker. John asserted Making Halloween costumes is fun and there is no reason to believe that he is violating the norms (for example, he is not using an ironic tone of voice). Hence Peter infers that "Making Halloween costumes is fun" is true given the standards of fun of John.

To summarise, what is linguistically communicated is the judge-neutral proposition "Making Halloween costumes is fun" which does not contain reference to any agent or standards of fun. The proposition gets a truth value once it is evaluated relative to someone's standard of fun. The hearer typically evaluates the proposition relative to her circumstance of evaluation. If the proposition is false it is rejected, as manifested by disagreements, or if it is true it is accepted and added to the stock of presuppositions. Furthermore, the act of assertion together with implicit knowledge of the norms that govern conversations enable hearers to infer certain information about the speakers, e.g. that they believe that the proposition they express is true given themselves as a judge.

\section{The problem}

In his (2007) paper, MacFarlane argues that moderate relativists cannot explain disagreements about taste because what counts as disagreement ought to depend on one's views on propositions. Since the moderate relativist's propositions depend on judges for their truth, there is genuine disagreement only when one agent accepts a proposition and another rejects the same proposition, and we hold all the parameters of evaluation fixed. According to MacFarlane, in the taste case there can be genuine disagreement only if the proposition is evaluated relative to the same judge and the speakers disagree on its truth. Recanati (2007) criticises the relativist accounts of disagreement on the same grounds.

But as we saw when formulating the argument for relativism, Kölbel and Lasersohn are not committed to there being genuine disagreements about taste. The criticism misses its target given that Kölbel and Lasersohn only take themselves to predict the appearance of disagreement.

However, there is a closely related problem which remains even when the relativist's argument against contextualism is formed in terms of appearance of disagreement. The relativist assumes that the formal difference of locating an element of the truth-conditions to the circumstance of evaluation instead of the proposition expressed makes for a difference in linguistic communication. The difference is supposed to be that since only the proposition (and not values of the 
How Moderate Relativists Should Explain the Appearance of Disagreements about Taste

circumstance of evaluation) is linguistically communicated, an assertion of a proposition and its negation causes an appearance of disagreement between the speakers.

But why should we think so? Both proposition and circumstance of evaluation are purely technical terms and we are yet to be shown the link between the formal structure and actual language use. However, we do know that the relativist is committed to the circumstance-dependence of some other expressions than taste predicates. Given that the proposition vs. parameters of evaluation distinction is supposed to be responsible for the appearance of disagreement, we need to look at other alleged cases of contradictory but circumstance-dependent propositions. In those cases as well there should be an intuition of disagreement, even if it is clear that the relevant circumstances of evaluation differ. Hence, cases like those of MacFarlane's and Recanati's can either be used as test cases for whether an expression is circumstance-relative, or to question the very idea of the relativist views of appearances of disagreement. If there is not a single case besides taste predicates where there is an appearance of disagreement when two contradicting contents are expressed, there is extremely meager grounds to claim that the relativist framework would have explained or even formally modeled the basis of the appearance of disagreement correctly.

Let us first look at a case of locations à la Recanati. Suppose you are in rainy London and you complain It's raining again. At that moment I call you from Berkeley and I utter It's wonderfully sunny. If relativism about locations is right I just expressed a proposition which contradicted what you said, but we do not get an appearance of disagreement.

Another popular case of parameter-relativity are times. Suppose that I just finished having lunch with you and you utter I'm totally full. Later, I listen to my voice mail and hear a message that you had left earlier which says Let's have lunch, I'm starving. Again, assuming relativism about times is right, the propositions you expressed contradict but there is no appearance of disagreement.

As far as these cases go, the relativist who is only motivated by the appearance of disagreements could simply take the data as evidence against construing times and locations as elements of the parameters of evaluation rather than the proposition expressed. But how about the case of possible worlds, the mother of all parameters of evaluation? Let me quote MacFarlane's case:

Consider Jane (who inhabits this world, the actual world) and June, her counterpart in another possible world. Jane asserts that Mars has two moons, and June denies this very proposition. Do they disagree? Not in any real way. Jane's assertion concerns our world, while June's concerns hers. If June lives in a world where Mars has three moons, her denial may be just as correct as Jane's assertion. (Nothing hinges here on the realist talk of worlds and counterparts. However you think of modality, it makes sense to ask whether in saying what one would have said, in 
Lodz Papers in Pragmatics 7.2 (2011)/Special Issue on Context and Contextualism: 223-240 DOI: $10.2478 / \mathrm{v} 10016-011-0012-7$

some counterfactual situation, one would have disagreed with what one actually did say. That you would have rejected the proposition you actually accepted is not sufficient for an affirmative answer to this question.) (MacFarlane 2007: 23)

I find MacFarlane's way of approaching the problem slightly too complicated to give rise to clear judgments, so let me consider a simpler case of an assertion that is intended to be true relative to a counterfactual world. For our case to work we need to add an assumption which is typically endorsed by the relativists: Certain expressions shift the circumstances of evaluation. For example, in Yesterday the prophet spoke the relativist about times takes yesterday to shift the time parameter so that we need to look at whether the embedded clause the prophet spoke is true on the day before the day of utterance. If it is true, then the whole sentence is true at the time of utterance. We will assume that we can likewise shift the world of evaluation to counterfactual or fictional worlds by suitable expressions.

Here is the case. Mary is describing to John how her life would have been if she had been filthy rich, using some such linguistic device as Imagine me to be filthy rich (and what follows is expressed by using the present tense.) Peter enters the room and hears her utter So my husband is a model, and everyone envies me. Peter thinks she is inventing bizarre lies and says Come on, your husband is no model!

At this stage we can imagine that to Peter it appears that there is disagreement between himself and Mary: he expressed a proposition which contradicts the proposition expressed by Mary. But Mary, knowing Peter did not hear the beginning of her monologue, realises his confusion so, for her, there is no appearance of disagreement. And as soon as she utters I was talking about how my life would have been if I'd studied finance instead of philosophy, the appearance of disagreement Peter has vanishes. As was emphasised earlier, the relevant understanding of there is an appearance of disagreement was one in which it thus appears to both/all speakers. Hence our case does not count as a case in which there is appearance of disagreement.

To conclude, there is no appearance of disagreement in the case of the world parameter. I want to emphasise that the problem is extremely serious: the world parameter provides the model for other parameters, and if no appearance of disagreement shows up in the cases of different worlds, then there is no argument whatsoever to claim that there should be an appearance of disagreement with other parameters.

If the relativist could make the case for at least some other parameters than the world where we get the appearance of disagreement, then they could try to argue that worlds somehow form an exception. But as we saw, times and locations do not create the appearance either. Hence I conclude that relativists such as Kölbel and Lasersohn have no grounds for claiming that contradictory but incomplete propositions create an appearance of disagreement. 
How Moderate Relativists Should Explain the Appearance of Disagreements about Taste

\section{Thoughts without representation}

In this section I suggest a way to understand the moderate relativist framework which can explain the appearance of disagreement of taste. The resulting view is moderately relativist only in accepting that the notion of an incomplete proposition (contents) whose truth is relative to more parameters than the world is theoretically useful. But I take monadic truth to be the basic notion of truth, and the relativised truth predicate to be derivative. Moreover, I take utterances to express propositions which get an absolute truth value.

The reason why I find the relativist framework useful is that it helps to characterise mental contents; in that respect the view put forward here is much influenced by Perry (1986) and Recanati (2007). But the view can also very naturally explain appearances of disagreements of taste which is our focus in this paper. Due to lack of space the picture is necessarily sketchy and at many points I will have to rely on asserting the view rather than arguing for it, but I hope the main idea becomes clear enough.

First, let us fix on some terminology: call an incomplete proposition together with the values of a circumstance of evaluation a complete proposition. A complete proposition is absolutely true or false. The values of the parameters which enter the complete proposition are determined by the context of utterance.

Call the way thoughts are encoded in the speaker's minds representations. The contents attributed to utterances and representations can be complete or incomplete propositions. We can think of them as structured propositions which consist of individuals, properties and relations. When a speaker represents each element of the complete proposition she expresses or thinks of, her representation matches the complete proposition.

What I want to argue following in the footsteps of Perry (1986) is that it is possible for a speaker to express a complete proposition without her having a matching representation. Which complete proposition is expressed is determined by the circumstance of evaluation of the context where the utterance takes place. Let me first illustrate the idea with examples, and then move on to the arguments that support the view.

Perry's own example is the case of Z-landers who do not represent locations in their thoughts. They have always lived in Z-land which is very small, they never travel and they do not know that there are other locations. When it rains they say It's raining, but they take rain to be a property, not a relation of raining-in-location. Hence their representations do not contain locations, but when they say It's raining, they express the proposition "It's raining in Z-land".

Now imagine Svetlana, a child who lives in a town located on the Krasnoyarsk Time zone. She has never heard of time zones but can read the clock. She utters It's 5 p.m.. Her utterance is true or false only if a time zone is provided but since 
Lodz Papers in Pragmatics 7.2 (2011)/Special Issue on Context and Contextualism: 223-240 DOI: $10.2478 / \mathrm{v} 10016-011-0012-7$

she does not know that, if we only look at what she represents, we get something less than truth-evaluable as the content of her utterance. But given the time zone she is in, we take her utterance to express the complete proposition "It's 5 p.m. in the Krasnoyarsk time zone".

Likewise with, for example, the relation of simultaneity: two events are simultaneous only once a frame of reference has been chosen. But many people do not represent simultaneity as a relation between objects, relative to a frame of reference. Still it seems that they are able to state truths about simultaneity: the frame of reference is provided by the situation. The claim is that in each of these cases the relevant element is provided by the environment so that the utterances get to express a complete proposition, even though the speakers' representations are not matching that complete proposition.

\section{Motivation for contents without representation}

To understand the motivation behind the view, let us look at the alternative ways to understand the above cases. Roughly speaking, in them the speakers either:

(1) say something that they do not think, or

(2) say something that is not truth-evaluable (since an element of the relation in question is left unspecified), or

(3) say something false. For example, there is no property of raining, only a relation raining-in-1, so it rains (simpliciter) is false.

I have recommended that we accept (1). The main argument is that we should do semantics so as to maximise truth or knowledge, all things considered. Option (1) is clearly the best option in this respect. But we do not want to maximise truth at the expense of completely severing the link between representations and propositions either. Another important constraint is that there is a causal link between the content expressed and its representation.

By the causal link between content and representation I mean that we (as theorists or as hearers) may only add elements of complete content which play a causally relevant role in the speaker's representation: call this relation tracking. For example, in each of our example cases the thoughts track the relevant phenomena where the speakers are. So by adding the missing element of content we are maximising true beliefs and utterances by making explicit an element that ties the content to what causes the representation. In general and ceteris paribus, we should give expressions semantic values which are best causally correlated with tokenings of those expressions. Another important motivation is to connect propositional content and action. If the Z-lander merely thinks, for example, a truth-valueless 
How Moderate Relativists Should Explain the Appearance of Disagreements about Taste

proposition "It's raining", there is no explanation for why he is carrying an umbrella. But once we attribute to him the thought It's raining in Z-land we understand his behaviour.

\section{Parameters of evaluation}

In cases where an element of complete content is not represented, Perry says the thoughts or utterances concern the element but are not about them. Here my understanding of the relation of concerning differs from that of relativists who sometimes refer to the same distinction (see e.g. MacFarlane 2009: 243).

As I emphasised in the examples above, a representation merely concerns an element of the complete proposition if it is provided by the situation but not represented. Moreover, I follow Perry in claiming that the situation should provide the value for the parameter invariantly, but here we need to be cautious due to ambiguity. It is the rule for how the value gets chosen which is invariant, not the value itself. For example, whoever utters here invariantly refers to the place they are in at the moment of utterance, but the referent is variant in the sense that it can be a different location.

By now I have only discussed the relation between a speaker who represents an incomplete proposition and what gets expressed, but how does communication work from the point of view of the hearer? The hearer may not represent the missing element either, but she will grasp the relevant complete proposition as long as her circumstance of evaluation gets the same values as the proposition that was expressed.

Essentially, what I have called the missing element corresponds to parameters in the circumstances of evaluation. The criteria for something to be a parameter of a circumstance of evaluation are the following:

(1) The value of the parameter is not represented by the speaker but it is required for the proposition expressed to be truth-evaluable.

(2) The value of the parameter is invariantly provided by the context of utterance of the speaker.

These criteria suggest a test for positing parameters: non-representation is accompanied by mistakes the hearer makes in evaluating the truth of what is said by others (or one's past self) under the following conditions: the value of the parameter is not the one that would be provided by one's own situation, and that difference causes a difference in truth-value. That is a consequence of (1) and (2): a value for the parameter is required for a truth-evaluable proposition, but it is the speaker's situation which provides the value. In these cases the hearer will rely on 
Lodz Papers in Pragmatics 7.2 (2011)/Special Issue on Context and Contextualism: 223-240 DOI: $10.2478 / \mathrm{v} 10016-011-0012-7$

her own circumstance of evaluation in evaluating the truth of the proposition which means that she is tracking the wrong situation. And when the value provided by her circumstance and that of the speaker differ regarding the truth-value the proposition would get, the hearer will be mistaken in that respect.

\section{Back to appearances of disagreements about taste}

The point of presenting the framework in the current context is to apply it to predicates of taste. I agree with relativists and contextualists that the truth of taste judgments depends on a judge, and I take the judge to be the speaker unless explicitly stated otherwise (by e.g. using operators such as Peter thinks that...).

However, I do not agree that speakers in ordinary cases are knowingly evaluating propositions relative to different judges. Instead, I take the judge not to be represented but merely provided invariantly by the situation: for each context of utterance, the value of the judge parameter is the speaker (or the speaker's standards of taste. The details do not matter at this point. As in every other case of non-represented parameters, the judge parameter may come to be represented when, for example, the agent is surrounded by people with very different standards of taste. At first that leads the agent to constantly disagree, and may ultimately lead her to represent standards of taste to make better sense of what is expressed by others, and by herself.

Now, regarding disagreements, I agree with MacFarlane and Recanati and take disagreement to be a matter of utterances of contradicting contents whose circumstances of evaluation share their values. But I do not think there are genuine disagreements of taste either except in very rare occasions, only confusions of which standards of taste are the relevant ones. ${ }^{5}$ Hence, I take the challenge to be that of explaining appearances of disagreements of taste.

The picture is as follows. Evaluative taste properties are not functions from objects to truth values, but functions from standards of taste and objects to truth

\footnotetext{
${ }^{5}$ Here is an example of a genuine disagreement of taste: Imagine two identical twins who are physically and mentally as alike as can be, and who like sweet flavours but dislike bitter flavours. Someone plays a trick and grinds a miracle fruit (synsepalum dulcificum, a berry which causes sour and bitter foods to taste sweet) in the drink of one of the twins. While the twin is under the influence of the berry they taste a bitter beer, and the tricked twin states This is delicious! The other twin is shocked (given their usual agreement about everything) and disagrees by saying But this is disgusting! Here it seems that the twins are genuinely disagreeing given that their standards of taste are the same (and if we assume that the miracle fruit did not actually change the standards of taste of the twin, only caused him to misperceive flavours). It also seems that the tricked twin is wrong, so nothing like faultless disagreement is going on here.
} 
How Moderate Relativists Should Explain the Appearance of Disagreements about Taste

values. But an agent may mistakenly represent those properties as functions from objects to truth values since the standard is provided invariantly by the environment: it is always the standard of taste of the agent. Hence the agents track relations like delicious given my standard of taste, and when they make taste judgements they express complete propositions which contain their standard of taste as an element. They evaluate the truth of their own utterances correctly since they track the right relation.

However, since they do not represent the parameter, they are mistaken regarding the content of what they said: They take the content to be a judge-neutral proposition. Not representing the judge also leads them to be often mistaken regarding the truth values of the taste statements of others. Here is an illustrative case:

Peter: "Semifreddi's morning buns are delicious.",

Mary: "No way, cinnamon is disgusting."

What Peter expressed was the complete proposition "Semifreddi's morning buns are delicious by Peter's standards of taste, at time t1, at @,. What Mary takes him to express is "Semifreddi's morning buns are delicious at time t1, at @." But delicious for Mary tracks the relation delicious by Mary's standards of taste. Hence the proposition she evaluates is actually "Semifreddi's morning buns are delicious by Mary's standards of taste, at time t1, at @." That proposition is false, which leads Mary to answer the way she does. There is no genuine disagreement since they are confused over the complete propositions expressed, but to them there is an appearance of disagreement since they are not representing the elements of the complete proposition, namely the standards parameter.

In short, an appearance of disagreement is due to an appearance of contradiction: of expressed content, or of content which is entailed by what is expressed. In our case, neither Peter or Mary take themselves to be asserting judgedependent propositions. Since morning buns taste a lot like cinnamon, one cannot find morning buns delicious if one finds cinnamon disgusting. Therefore, Peter's and Mary's assertions appear to contradict each other when one does not fill in the judge parameters. Since they do not fill in the judge parameters, it appears to both speakers that they are disagreeing.

\footnotetext{
${ }^{6}$ Morning buns are like cinnamon rolls but they are made of flaky croissant dough and do not have frosting on top.
} 
Lodz Papers in Pragmatics 7.2 (2011)/Special Issue on Context and Contextualism: 223-240 DOI: 10.2478/v10016-011-0012-7

\section{Conclusion}

The key difference between the view suggested here and views endorsed by relativists such as Kölbel, Lasersohn and Recanati is in the cognitive status of the circumstances of evaluation. I have argued that the point of locating elements in the circumstances instead of content has to do with representation: what is not represented but is required for a truth-evaluable proposition to be expressed is located at the circumstance of evaluation.

Kölbel, Lasersohn and Recanati all hold that the elements of the circumstances are represented too, and that one can shift between circumstances as when evaluating a taste statement from another person's point of view. I have argued that one is able to do that only once the element has become represented, and hence is no longer an element of a circumstance but a part of content.

The same basic difference underlies how I understand Perry's concern vs. about relation. I take thoughts or utterances to concern an element only when the element is not represented, whereas the relativists seem to correlate the difference with that of content and circumstance: content is about elements, circumstance concerns elements. But what is missing from their picture is the explanation of how this formal difference relates to language use or understanding. I take that to be the true challenge in making sense of semantic relativism.

\section{References}

Grice, Paul. 1989. Studies in the Way of Words. Cambridge: Harvard University Press.

Kaplan, David. 1989. Demonstratives. In: Joseph Almog, John Perry, and Howard Wettstein (eds.), Themes from Kaplan. Oxford: Oxford University Press.

Kölbel, Max. 2002. Truth Without Objectivity. London: Routledge.

—. 2003. Faultless disagreement. Proceedings of the Aristotelian Society 104: 53 73.

—. 2009. The evidence for relativism. Synthese 166: 375-395.

Lasersohn, Peter. 2005. Context dependence, disagreement, and predicates of personal taste. Linguistics and Philosophy 28: 643-686.

MacFarlane, John. 2007. Relativism and disagreement. Philosophical Studies 132: $17-31$.

—. 2009. Nonindexical contextualism. Synthese 166: 231-350.

Perry, John. 1986. Thought without representation. Proceedings of the Aristotelian Society 60: 263-283.

Recanati, François. 2007. Perspectival Thought: A Plea for (Moderate) Relativism. Oxford: Oxford University Press. 
How Moderate Relativists Should Explain the Appearance of Disagreements about Taste

Stalnaker, Robert. 1978. Assertion. In: Syntax and Semantics 9. New York: Academic Press.

Stephenson, Tamina. 2007. Judge dependence, epistemic modals and predicates of personal taste. Linguistics and Philosophy 30(4): 487-525.

Sundell, Timothy. 2010. Disagreements about taste. Philosophical Studies 155 (2): 267-288.

\section{About the Author}

Sanna Hirvonen is a $\mathrm{PhD}$ student at the Department of Philosophy at University College, London. Her work is centered on the philosophy of language, more specifically on the question of whether an agent's perspective affects semantics of predicates of taste, and if so, how. 